\title{
ENHANCING PV AND WIND HYBRID SYSTEM CONTROL USING NEURAL NETWORKS
}

\author{
Mukesh Nargesh \\ M.tech Scholar \\ Department of Electrical and Electronics \\ Oriental University, Indore, M.P., India
}

\begin{abstract}
During the sooner years, mutt sunarranged breeze power structures containing photovoltaic (PV) and wind generators are wont to oblige the irregularity issue of interminable force age units. The improved appearing and control plans for a framework tied cross assortment $\mathrm{PV}$-wind structure is brought inside the vitality examine work. the premier remarkable point following unequivocally "MPPT" figuring close by controlling the pitch point are utilized, solely, for the PV framework and wind age to achieve the preeminent silly force for a couple of sporadic outside environment conditions. An all-inclusive explanation work orchestrate sliding mode alluded to as the RBFNSM strategy is utilized to manage the contribute edge the breeze essentialness framework, while the PV structure utilizes a relative crucial helper controller outfitted with the woolen addition getting ready for sales to improve the transient state and moderate the settling time to ensure the reliable nature of the referenced structure. to check the proposed control plan's common sense, MATLAB re-foundations are done under different conditions of the breeze speed also as sun-arranged light. The got outcomes show the ampleness of the versatile MPPT method to deal with the chief fundamental force under testing conditions. the advantages of the made arrangements are rapidly and absolutely following the first uncommon force yield of the half and half PV-wind framework. Additionally, the office spilling between the utility cross section and in this way the cream source with a fast transient reaction and improved quality execution is adequately controlled utilizing the offered plans.
\end{abstract}

Keywords: PV, Wind, Hybrid, Neural networks

\section{INTRODUCTION}

The issue of controlling the genuine power yield of assembling units considering changes in system repeat

\author{
Dr Dolly Thankachan \\ Associate Professor and Head \\ Department of Electrical and Electronics \\ Oriental University, Indore, M.P., India
}

and tie-line power exchange inside decided cutoff focuses is comprehended as weight repeat control (LFC). it's for the chief part saw as a touch of modified age control (AGC) and is basic inside the action and control of power structures [1]. Immense degree power systems are conventionally made wild districts or areas talking with clear social affairs of generators. The control an area may have the mix of warm, hydro, gas, nuclear, manageable force sources, at that point on [2]. during an in every practical sense interconnected power structure, the age normally contains a blend of warm, hydro nuclear and gas power age. Regardless, because of their high viability, nuclear plants are typically kept at base weight. Gas power age is perfect for satisfying the varying burden need and is typically wont to fulfil top needs. Keeping in observe the current power circumstance, blend of multisource generators during a control area with their relating participation factors is dynamically common sense for the examination of LFC.

The researchers over the planet are attempting to propose two or three methods for LFC of force structures so on proceed with the system repeat and tie line stream at their arranged characteristics during standard action and moreover during little aggravations. In [12], a fundamental composing review on the AGC of force systems has been presented. it's seen from composing review, that the more prominent a piece of the LFC works are finished on two locale hydro-warm or warm systems. it's seen that broad research work is continuing to propose better AGC structures snared in to ebb and flow control speculation [2], neural framework, cushioned system theory, fortress learning and ANFIS approach. Be that since it might, these impelled methodologies are jumbled and wish shared characteristic of customers to those techniques during along these lines reducing their genuine nature. in any case, an old style text style Proportional Integral Derivative (PID) controller remain a planner's supported choice because of its assistant ease, unfaltering quality, and in this way the extraordinary extent among displays and cost. Moreover, it in like manner offers improved remarkable illustrating, lower customer capacity necessities, and immaterial headway effort, which are huge issues with in structuring practice. 
As of late, new man-made cognizance-based strategies are proposed to smooth out the PI/PID controller parameters for AGC system. In [3], two or three old style text style controller structures, for example, I, PI, Integral Derivative (ID), PID and Integral Double Derivative (IDD) are applied and their introduction has been broke down for an AGC system. Work in [3] have demonstrated that Bacterial Foraging Optimization Algorithm (BFOA) improved controller gives favored execution over GA based controllers and conventional controllers for an interconnected power structure. In [3], a balanced objective work using Integral of your time expanded by Absolute estimation of Error (ITAE), damping extent of winning eigen regards and settling time is proposed where the PI controller parameters are overhauled using differential headway (DE) figuring and in this way the results are differentiated and BFOA and GA smoothed out ITAE based PI controller to bring up its power. Composing survey similarly shows that for the most part AC tie-lines are used for the interconnection of multizone power systems and lesser thought is given to ACDC equivalent tie lines. Work have uncovered in [5] a multi-source age including warm hydro-gas systems, considering HVDC interface related in comparing with existing AC associate for settling repeat faltering and used an ideal yield analysis controller for repeat change.

\section{LITERATURE REVIEW}

Work in [6] have considered the two-zone non warm structures and used BFOA to propel increases of PI controller. The results are differentiated and individuals got from innate count and normal procedure. to bring up the reasonability of their proposed controller, affectability assessment is in like manner performed. Work in [7] researched the 2 domain warm system with agent dead band nonlinearity. during this paper, different old style textual style target limits are considered to ask the expansion of PI controller using ferocity based PSO (CPSO) and differentiated and individuals procured by their proposed target work. Dynamic responses are in like manner given for both conventional and proposed target limits. Work in [8] considered a reasonable AGC systems considering GRC, dead band, low spend channel and, time delay are constrained on representative and turbine of the structure. GA is utilized to propel the expansion of the controllers. Dynamic presentations of the three-zone system without considering and with considering the above physical objectives are considered. Work in [9] have proposed maintainable force source power ages, for example, turbine generator, work unit, photo voltaic system and twofold layer capacitor bank for limit. an effect strategy has been proposed to direct the repeat of the creamer system. Work in $[10,11]$ have considered the pile repeat control arrangement intertwining the correspondence delay inside the framework. $\mathrm{H} \infty$ control is proposed using direct structure uneven characters considering correspondence delay.
Work in [12] have examined the usage of false neural framework based ANFIS because of effect AGC of a 3 conflicting area watery system. ANFIS controller unites the upsides of fleecy controller even as smart response and adaptability nature of ANN. they need proposed

this woman use of ANFIS on account of effect a 3 conflicting zone watery system with GRC agonizing about trouble during a lone zone even as out and out locales. Their examination shows the improved presentation of ANFIS controller in assessment with the ordinary imperative controllers. Work in [13] have proposed cushy $\mathrm{C}$ infers batching procedure for load repeat control. The introduction of the proposed controller is differentiated and soft reason control and conventional control for two-zone even as a three area AGC structure with GRC. Work in [14] have proposed an eager learning based PI controller for two-locale interconnected AGC system. The dynamic shows of standard PI, feathery method of reasoning, blend neurocushioned and proposed energetic learning based PI controllers are considered. Work in [15] have proposed another phony bumble bee state (ABC) figuring to a twodomain warm power system to tune the PI and PID controllers. In like manner, the life of the proposed figuring is attempted with parameter assortment and change in stacking. Work in [16] have proposed 2-level of chance (DOF) PID controller for LFC of two zone interconnected power structure with congressperson dead band nonlinearity. Differential progression (DE) technique is utilized to appear to be through the ideal controller parameters. Work in [16] have proposed a variable structure feathery expansion arranging controller for clarifying two-domain interconnected LFC. The presentation of the proposed controller is differentiated and individuals got from Ziegler Nichols (ZN) system with customary and GA for search space improvement. it's found that the proposed controller performs better than resulting two strategies. The recently referenced works are represented vertical consolidated utility masterminded power systems.

The deregulated condition consolidates age, transmission and scattering associations. The recently referenced methodologies for AGC can't be applied genuinely to the AGC of deregulated power structure. Under deregulation several control procedures are represented in [16]. In these references, the effect of deregulation in LFC issue has been gone to. the worth based movement using AGC test framework and exhibiting with multiplication results are proposed in references [17], independently. Regardless, the makers have considered the proposed system for essential two-district with two GENCOs. In [18] versatile neural frameworks-based methodology is proposed for load repeat controller structure during a deregulated area. In [19], a genuine coded inherited count (RGA) for upgrade of basic expansion and tendency factor is proposed which is applied to three-locale AGC 
structure after deregulation. Each region includes two GENCOS, where GENCOs of first and second locales involve turbine and third area contains hydro turbine. The results gained by RGA are differentiated and individuals got from conventional technique.

Work in [20] have proposed an AGC scheme where, improvement of dynamic responses of AGC is gotten under open market using TCPS in plan with the tie-line. Examination reveals that a TCPS is very fit smothering the repeat and tie-line power movements sufficiently when appeared differently in relation to those got without TCPS. The customized age control of TCPS based watery structure under open market circumstance using fleecy basis controller has been represented in [20]. Dynamic responses of cushioned justification controller and normal fundamental controller are looked at for little inconvenience of weight changes. In [20], maker proposed a non whole number controller for multi-locale warm structure under deregulated condition. The shows of two or three old style textual style controllers are differentiated and non whole number control. In [21], the maker proposed the LFC of an interconnected two-district multi unit warm power structure in reconstructed condition. To smother the transient movements, redox stream batteries at load point and interline power stream controller (IPFC) in course of action with tie-line are used. BFOA is utilized to fortify the controller parameters. The recently referenced composing survey isn't far reaching an identical number of a researchers consider are unendingly investigating the AGC issue and its various issues after deregulation.

\section{PROPOSED SYSTEM}

The block diagram of the proposed model can be shown from the following figure,

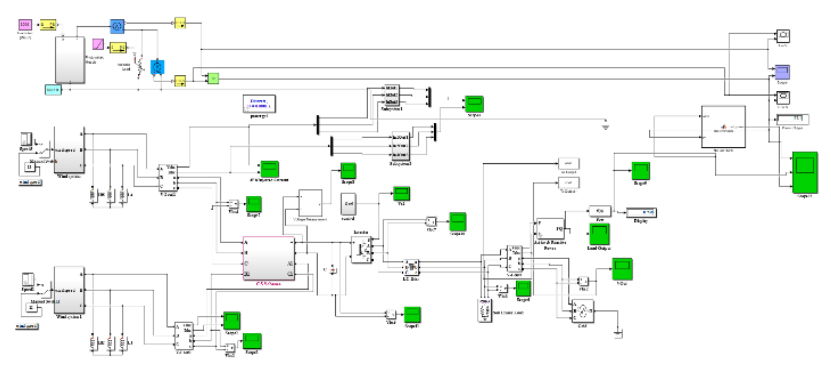

Figure. Proposed model

The model has the following working principle,

- Wind and PV systems work in synchronization
- Both of the systems are controlled by a Neural Network algorithm, which works as shown in figure 1

- The rectifier and PWSM blocks convert the power into filtered form

- The inverter is used to feed the power to the grid

- Finally, the output power from both the PV and Wind systems is fed to the grid for an enhanced output performance

An interconnected power system is included several domains. For the reasonable movement of force structures, both consistent repeat and predictable tie-line power exchange are needed. In each zone, a modified age controller (AGC) screens the system repeat and tie-line streams, registers web change inside the age required (for the preeminent part insinuated as an area control botch ACE) and changes the set circumstance of the generators inside the locale to remain the time typical of the ACE at an espresso worth [59]. Henceforth ACE, which is described as a prompt blend of power net-exchange and repeat deviations, is normally taken in light of the fact that the controlled yield of AGC. since the ACE is made a beeline for zero by the AGC, both repeat and tie-line power botches are constrained to zeros [60]. AGC limit are regularly observed as a managerial control work which tries to arrange the age design inside a domain to the example of the indiscriminately changing load of the proportionate or other area, to remain the system repeat and accordingly the tie-line power stream close to booked worth. the occasion in size and multifaceted nature of electrical power systems close by increase in power demand has required the utilization of shrewd structures that join data, procedures and ways of thinking from various hotspots for the proceeded with control of force systems.

The authorities over the planet are continually proposing several approachs for AGC of power structures so on proceed with the system repeat and tie line stream at their arranged characteristics during run of the mill movement and moreover during little aggravations. There has been amazing exploration work attempting to propose better AGC structures snared in to savvy procedures, for example, neural framework, feathery system theory, fortress learning and ANFIS approach. Furthermore, unique man-made awareness based smoothing out techniques are proposed to upgrade the introduction of a power structure. These systems consolidate particle swarm upgrade, differential turn of events, multiobjective transformative computation and NSGA-II, etc. Bacterial Foraging Optimization Algorithm (BFOA), proposed by Passino, is another comer to the gathering of nature-breathed life into improvement estimations. BFOA relies upon social and supportive practices found in nature. 
Mulling over the more than, an endeavor has been made for the ideal structure of cross variety $\mathrm{NN}$ based PI controller for AGC in two-domain interconnected power system. the motivation behind the current work is twofold: (I) to display the benefits of $\mathrm{NN}$ over various strategies, for example, PSO, BFOA and GA which are as of late presented inside the composition for the equivalent issue and (ii) to bring up the upsides of using a changed objective work snared in to Integral Time copied Absolute Error (ITAE) measures, damping extent of transcendent eigenvalues and settling times of repeat and tie-line power deviations with fitting weight coefficients to furthermore manufacture the shows of the power structure.

The arrangement issue is characterized as a headway issue and NN is utilized to appear for perfect controller parameters. Generations results are acquainted with call attention to the suitability of the proposed controller in giving incredible damping trademark to structure movements over a decent extent of stacking conditions, disrupting impact and system parameters.

The following parameters are taken for each of the blocks,

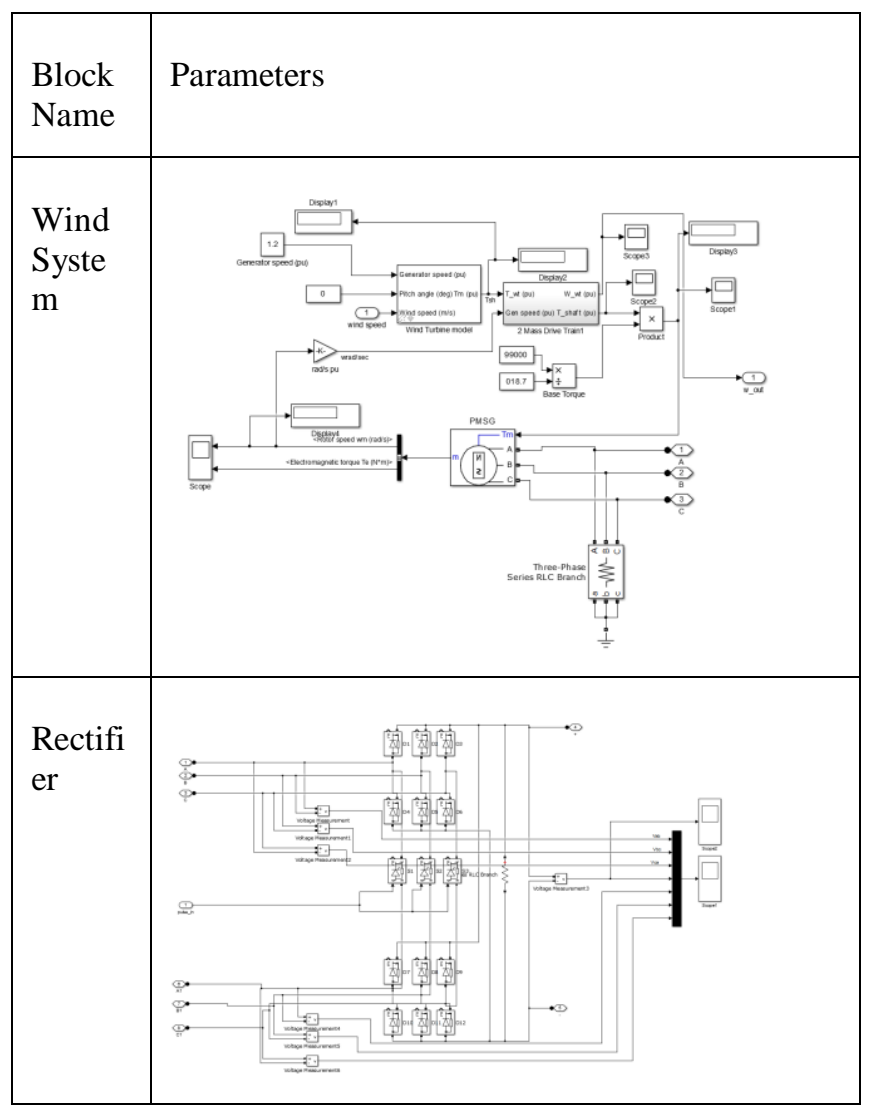

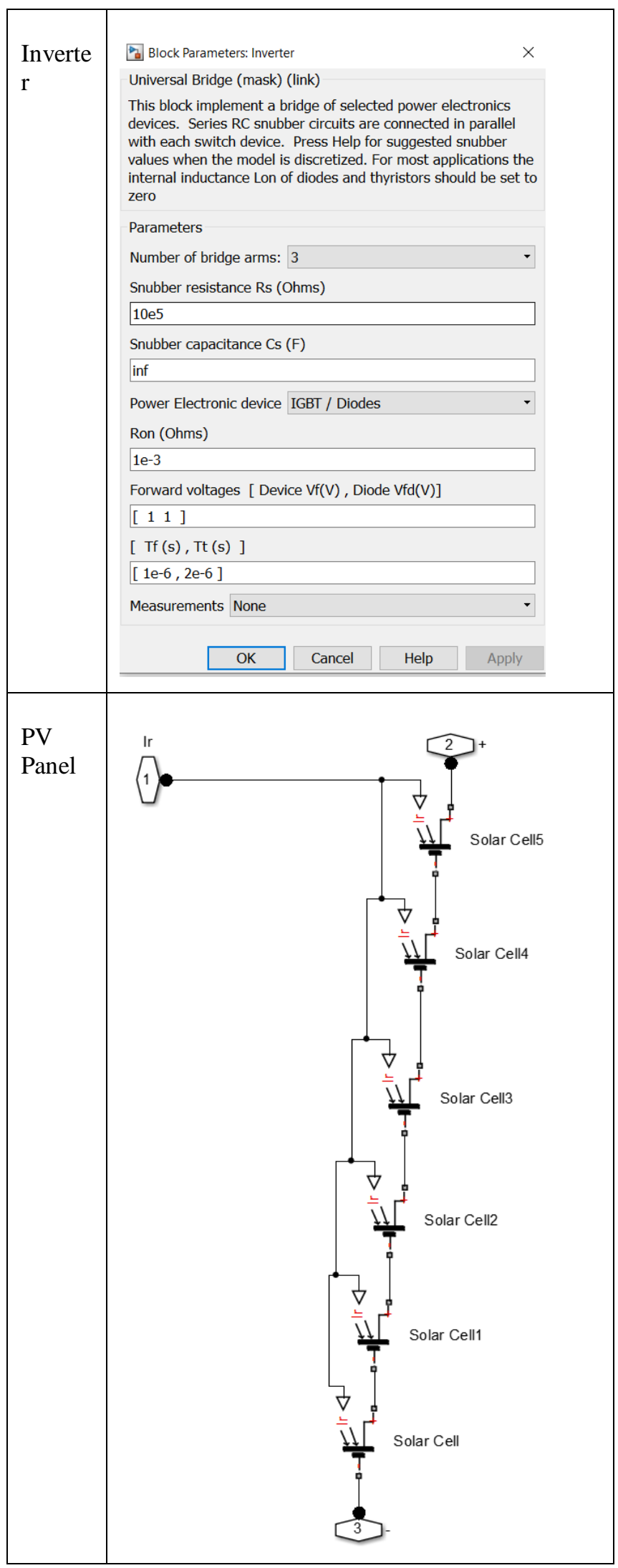


International Journal of Engineering Applied Sciences and Technology, 2020

Vol. 5, Issue 2, ISSN No. 2455-2143, Pages 471-478

Published Online June 2020 in IJEAST (http://www.ijeast.com)

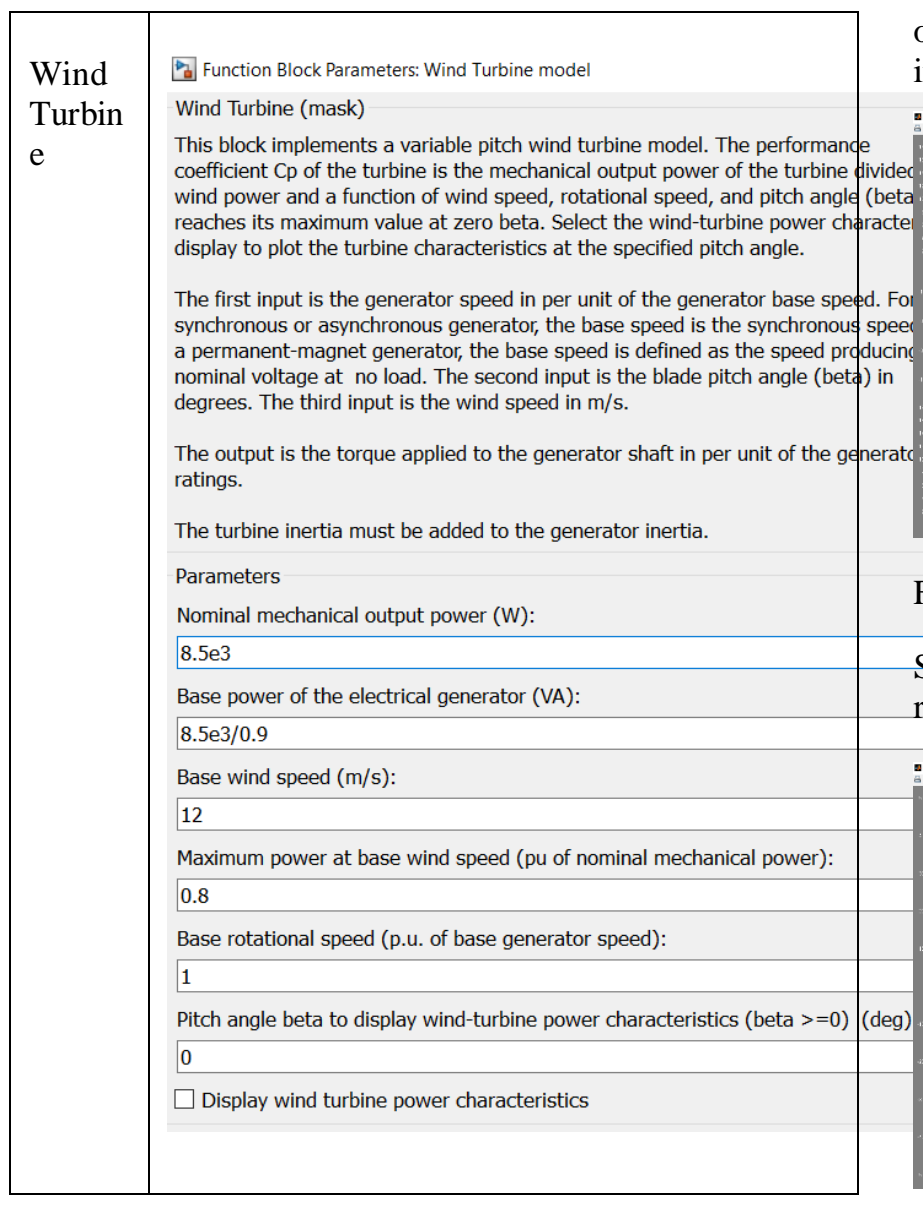

Table. The details about each of the blocks

In this assessment, half and half and adjust directors of $\mathrm{NN}$ are used to upgrade the introduction of the $\mathrm{NN}$ strategy. NN benefts a modest capacity of making an amicability among examination and misuse, with the top objective that it explores the chase space and undertakings good areas that have proper course of action. Taking everything into account, in colossal degree upgrade issues, the NN could be not able to arrive at a quick association and trap in close by perfect. that is the inspiration driving why improved NN has been presented. The improved NN strategy knew about beat two or three challenges of headway procedures when the segment of the troublesome additions and to achieve a speedier gathering. during this way, the improved NN method has been proposed to guarantee legitimate consideration of search space related to the extent of progress factors and showing up at a suitable intermixing of overall perfect. Improved NN execution for fathoming the arrangement of the cross variety system snared in to fiscal and specific records.

\section{RESULT ANALYSIS}

First, we observed the voltage, current and power when PV, Wind systems are hybridized. From the figure we can observe a change in the PV values at different time instants,

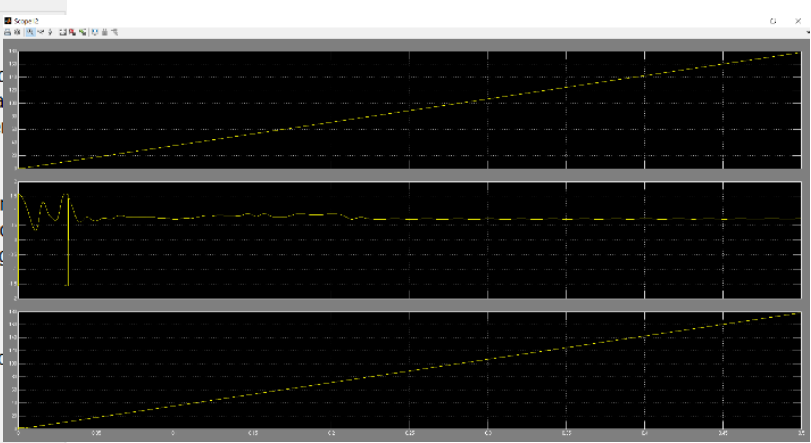

Fig 1 Output power for Wind and PV models

Similar observations are made for the voltages, and results are showcased in figure 2 as follows,

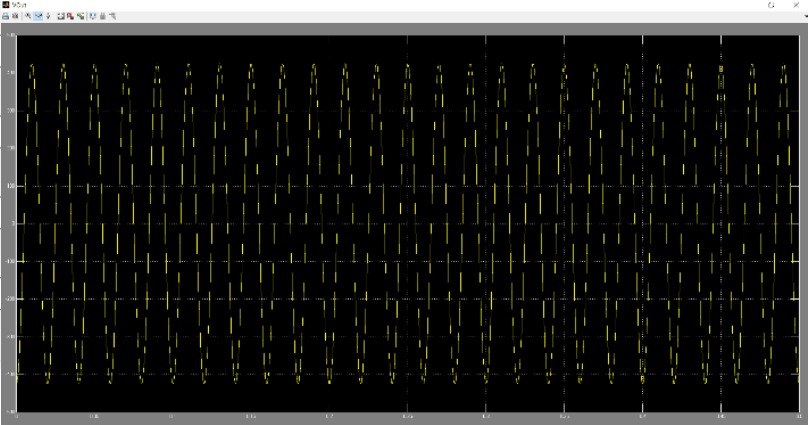

Fig 2. Output voltages when both systems are combined

From the figures we can observe that the voltages and currents are varying abruptly and the overall system stability is compromised due to addition of faults. This needs to be addressed, but first let's understand the effect of varying the irradiance on the output of the PV array. These results are given from the figures 3, 4, 5 and 6 as follows. As we can see, the results showcase that an increase in the irradiance level should always increase the power, voltage and current outputs of the PV array. But, this power is limited by the PV model used, and further increasing the irradiance will not vary the power output.

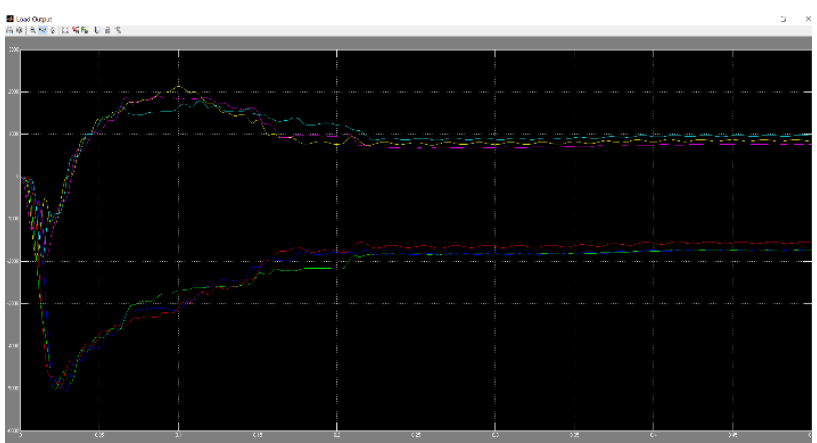

Fig 3 Variations in output for different PV and Wind systems 


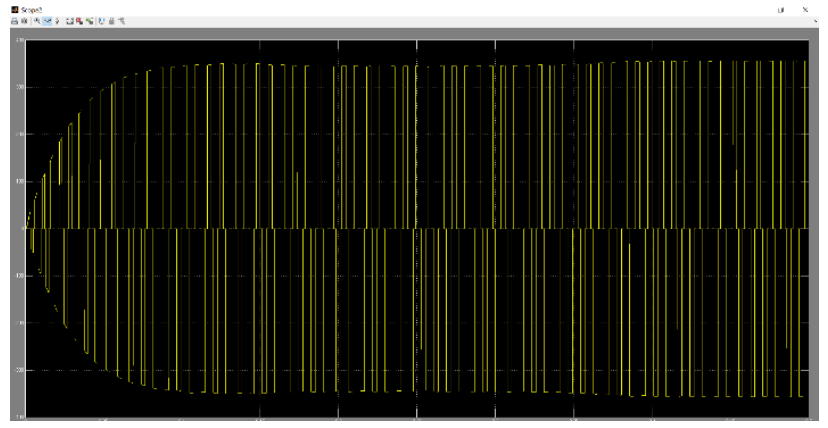

Fig4 Variation of pulses obtained from PV array when Irradiance $=1000 \mathrm{~W} / \mathrm{m} 2$ and temperature $=25$ degree Celsius

From the results we can observe that,

- The hybrid system is able to obtain the maximum allowed output power

- Due to NN the stability of the circuit is optimum

- There are no spikes, lags or swings in the output voltage

- Current waveforms are stable due to NN

- $\mathrm{NN}$ is able to obtain all these results with minimum power wastage and maximum circuit utilization

- Similar results are obtained for the power of NN output

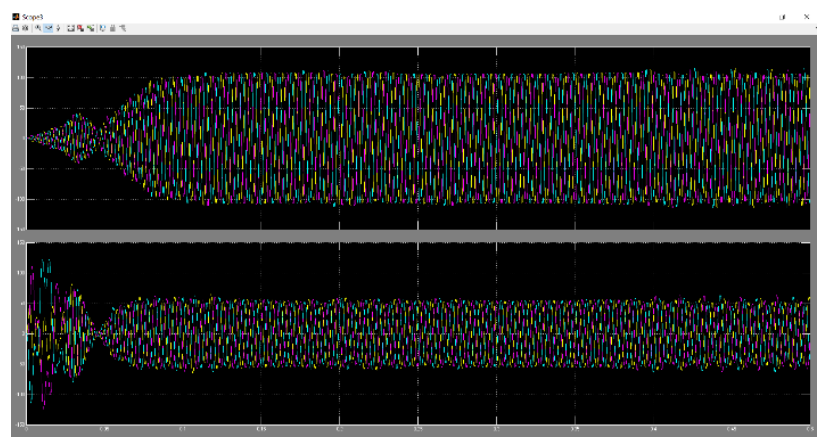

Fig 5 Neural Network-based output

When Neural Network is connected the output follows a proper sinusoidal pattern as expected. This pattern indicates that the circuit is constantly supplying high quality power to the output grid.

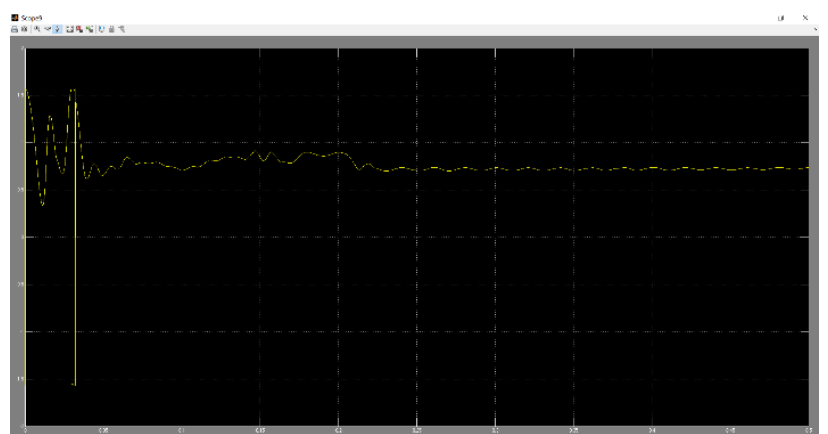

Fig 6 Output of Neural Network algorithm

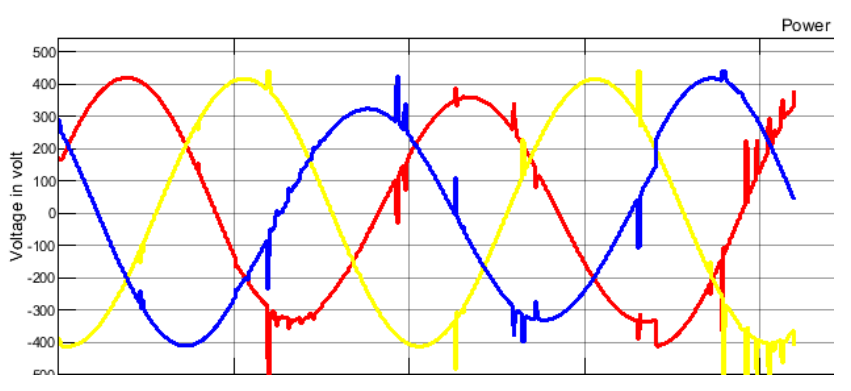

Fig 7. Three Phase voltage at the output of three phase inverter when irradiance $=800 \mathrm{~W} / \mathrm{m} 2$

Similarly, irradiance variation outputs can be observed from following figure,

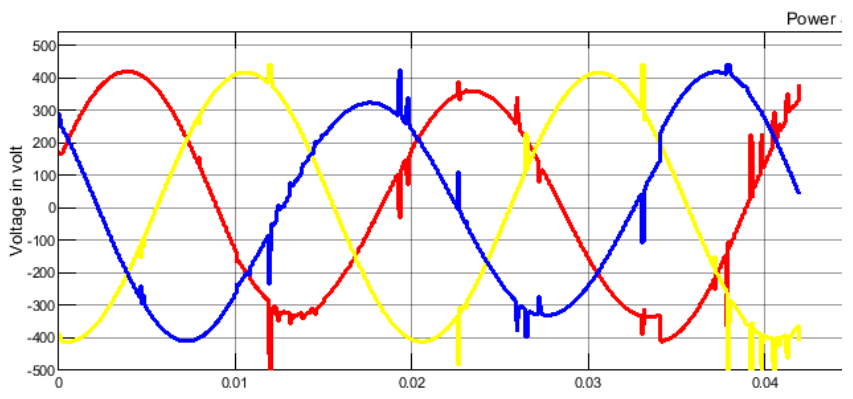

Fig 8. Three Phase voltage at the output of three phase inverter when irradiance $=1000 \mathrm{~W} / \mathrm{m} 2$

From these results we can observe that the disturbances in the power are mitigated due to the usage of Neural Network with Hybrid system, and the system's efficiency is improved.

\section{CONCLUSION}

Improved control strategies and plan of a system tied cream $\mathrm{PV}$-wind structure were proposed during this paper. The suggested procedures were executed using FGS-PID and RBFNSM plans for PV and WT systems during a creamer power structure, separately. The prescribed philosophies give effective abilities to the blend power system to handle the first raised power from sun controlled and wind imperativeness resources. The results procured from the amusements indicated the reasonability of proposed strategies for both transient and predictable states by damping out transient, diminishing getting ready time, and improving constancy of the system. The FGS-PID and RBFNSM strategies rapidly and appropriately track the preeminent amazing yield of the blend PV-wind structure. In addition, a beneficial power stream control between the utility cross section and along these lines the creamer source with the quick transient response and improved robustness execution was practiced using the proposed plans. it's fundamental that the auxiliary $\mathrm{dP} / \mathrm{dV}$ should be resolved quickly inside 


\section{International Journal of Engineering Applied Sciences and Technology, 2020 \\ Vol. 5, Issue 2, ISSN No. 2455-2143, Pages 471-478 \\ Published Online June 2020 in IJEAST (http://www.ijeast.com)}

the presented approach which may be clear using the open gear like FPGA chip which is fit realizing the more extended term proposed plot.

\section{REFERENCES}

[1] Ali E. S. and Abd-Elazim S. M. (2011)"Minuscule life forms scavenging improvement count based weight repeat controller for interconnected power structure", in Electric force and Energy Systems, Vol. 33, , pp. 633638.

[2] Gozde H. and Taplamacioglu M. C., (2011)"Modified age control application with foolishness based particle swarm headway during a warm power structure" Electric force and Energy Systems,, Vol. 33, pp. 8-16.

[3] Golpira H. and Bevrani, H. (2011)"Utilization of GA progression for modified age control structure in an interconnected power system", Energy Conversion and Management, Vol.52, pp. 2247-2255.

[4] Nayeripour M., Hoseintabar M. and Niknam T., (2011) "Repeat deviation control by coordination control of FC and twofold layer capacitor in an autonomous creamer maintainable force source power age system", Renewable Energy, Vol. 36, pp. 1741-1746.

[5] R. Dey Ghosh, Bar G., and. Rakshit A, (2012)"Hळo load repeat control of interconnected power structures with correspondence delays", electric force and Energy Systems, Vol.42, pp. 672-684.

[6] Khuntia S. R., and Panda S., (2012) "Propagation concentrate for customized age control of a multi-domain power structure by ANFIS approach", Applied Soft Computing, Vol.12, pp. 333-341.

[7] Sudha K. R., Raju Y. B. and Sekhar A. C., (2012) "Cushy C-Means gathering for overwhelming decentralized weight repeat control of interconnected power structure with age rate basic", Electric force and Energy Systems,, Vol. 37, pp. 58-66.

[8] Farhangi R., Boroushaki M., and Hosseini S. H., (2012) "Weight repeat control of interconnected power structure using energetic learning-based shrewd controller", electric force and Energy Systems, Vol. 36, pp. 76-83.

[9] Gozde H., Taplamacioglu M. C. and Kocaarslan I ., (2012)"Relative execution assessment of Artificial Bee Colony figuring in customized age control for interconnected warm power structure", Electric force and Energy Systems, Vol. 42, pp. 167-178.
[10] Sahu R. K., Panda S., and Thrashing U. K., (2013)"DE propelled equivalent 2-DOF PID controller for load repeat control of force structure with agent deadband nonlinearity", electric force and Energy Systems, Vol.49, pp. 19-33.

[11]. Chandrakala K. R. M. V, Balamurugan S.and Sankaranarayanan K., (2013) "Variable structure cushy expansion arranging based weight repeat controller for multi source multi zone hydro warm system", electric force and Energy Systems, Vol.53, pp. 375-381.

[12] Chritie R. D.and Bose A., (1996) "Weight repeat control issues in power structure action after deregulation", IEEE Transactions on Power Systems, Vol. 11 (3), pp. 1191-1200.

[13] Kumar J., Scrubber NG. K. and Sheble, G. B. (1997)"AGC test framework for cost based movement, Part I: A model", IEEE Transactions on Power Systems, Vol. 2 (12), pp. 527-532.

[14] Kumar J., Scrubber NG. K. and Sheble, G. B., (1997) "AGC test framework for cost based movement, Part II: logical investigation results", IEEE Transactions on Power Systems, Vol. 2 (12), pp. 533-538.

[15] Bakken B. H.and Grande O. S., (1998) "Customized age control during a deregulated power structure", IEEE Transactions on Power Systems, Vol. 13 (4), pp. 14011406.

[16] Meliopoulos A. P. S., Cokkinides G. J. and Bakirtzis A. G., (1999) "Weight repeat control organization during a deregulated circumstance", Decision Support Systems, Vol. 24, pp. 243-250.

[17] Bevrani H., (1999) "Lessened $\mu$-based weight repeat controller during a deregulated power structure condition", Proc. of fourteenth Int. Power System Conf., Iran, pp.1-9.

[18] Bevrani H., (1999) "Ground-breaking trouble repeat controller during a deregulated circumstance: A $\mu$ association technique", Proc. of IEEE Int. Conf. on Control Applications, pp. 616-621.

[19] Bevrani.H. Teshnehlab M., (2000) "Weight repeat controller structure during a deregulated circumstance using versatile neural frameworks", Proc. of fifteenth Int. Power System Conf., 2000, pp. 1-6.

[20] Donde V., Pai M. A. and Hiskens I. A., (2001)"Reenactment and improvement in an AGC structure after deregulation", IEEE Transactions on Power Systems, Vol. 16 (3), 2001, pp. 481-489. 
[21] Arroyo J. M. and Conejo A. J., (2002) "Perfect response of a power generator to essentialness, AGC, and spare pool-based markets", IEEE Transactions on Power Systems, Vol. 17 (2), 2002, pp. 404-410. 